\title{
A Comparative Research on Proving: The Case of Prospective Mathematics Teachers
}

\author{
Gülçin Oflaz ${ }^{1}$, Kübra Polat ${ }^{1}$, Duygu Altaylı Özgül ${ }^{1}$, Mario Alcaide ${ }^{2} \&$ José Carrillo $^{2}$ \\ ${ }^{1}$ Cumhuriyet University, Faculty of Education, Sivas, Turkey \\ ${ }^{2}$ University of Huelva, Faculty of Education, Huelva, Spain \\ Correspondence: Gülçin Oflaz, Cumhuriyet University, Faculty of Education, Department of Mathematics and \\ Science Education, 58140, Sivas, Turkey. e-mail: erengulcin3@ hotmail.com
}

Received: July 6, 2019 Accepted: August 9, 2019 Online Published: October 8, 2019

doi:10.5539/hes.v9n4p92 URL: https://doi.org/10.5539/hes.v9n4p92

\begin{abstract}
It is of critical importance, in particular, for mathematics teachers who will teach future generations to understand and do mathematical proofs. It is important to determine future teachers' beliefs about and difficulties with proofs because their knowledge of this issue affects their teaching. This study aims to determine and compare the proof schemes of prospective mathematics teachers from two state universities, one in Turkey and the other in Spain. The case study was conducted within this study. The participants were 51 prospective teachers at their second year from the department of teaching mathematics education at Huelva University in Spain and 45 prospective teachers from the department of teaching mathematics education at Cumhuriyet University in Turkey. The Proof Test consisted of four questions about proofs for parallelograms. Semi-structured interviews were subsequently conducted to investigate the prospective teachers' responses in-depth. The findings suggest that prospective teachers from Turkey and Spain indicated affinity in proving. The majority of the prospective mathematics teachers were either unable to complete the proof or completed the proof in an inaccurate way.
\end{abstract}

Keywords: Proof schemes, comparative studies, prospective teacher, geometrical reasoning

\section{Introduction}

Proof is a keystone of mathematical thinking. Being competent at proving is of critical importance for mathematics teachers who will teach future generations to understand and do mathematical proofs (VanSpronsen, 2008). However, a vast majority of university mathematics students have problems understanding and doing proofs (Coe \& Ruthven, 1994; Martin \& Harel, 1989; Oflaz, Bulut \& Akçakın, 2016). The fact that students do not understand what proofs are or their function underlies these problems. Students who do not know how to write a proof prefer to memorize it instead of understanding it (Moore, 1994). It is important to determine future teachers' beliefs about and difficulties with proofs because their knowledge of this issue affects their teaching. This study aims to determine and compare the proof schemes of prospective mathematics teachers from two state universities, one in Turkey and the other in Spain. The interactivity and variety of mathematics education studies enable international comparison studies (Xsenofontos, 2010).

\subsection{Theoretical Framework}

The proof is a logical and deductive expression. According to Harel and Sowder (1998), proofs are the arguments that people produce to convince themselves and others about the accuracy of an expression. Therefore, proving has the goals of researching and persuading. While research is an action aimed at eliminating one's own doubts regarding the accuracy of a claim, persuading is an action aimed at eliminating others' doubts regarding its accuracy (Harel, 2008).

Sometimes, in the teaching contexts, the emphasis on proofs is given to its function as confirmation of an expression. But the history of mathematics tells us that it is more important for mathematicians to know why a statement is correct than to know that it is correct (Hersh, 1993). This also holds true in teaching proofs. Students should be shown why a statement is correct, rather than showing that it is correct because sense-making occurs when the proof and explanation are given together (Dreyfus, 1999). At this point one should reflect not only on proofs, but on proving. Mathematical proof is a complex activity that produces an assumption with supportive arguments using complex logical argumentation processes. The proof that is produced at the end is only a part of 
this process (Hilbert, Renkl, Kessler \& Reiss, 2008), the process of proving, which is an important mental task in mathematics. Therefore, understanding proof-related concepts, constructing proofs and understanding them are skills that students need to develop. However, students experience many difficulties with constructing and understanding proofs (Ernest, 1984; Hersh, 1993; Hilbert et al., 2008). Understanding mathematics occurs when the processes of intuition, trial, error, estimation and assumption take place successively, but the order of theorem, proof and example is generally followed in mathematics classrooms, becoming mathematical proof "a mental experiment independent of content" (Almeida, 2003, pp. 479). The structure of proofs, its requirements, are transversal amongst the mathematical contents, but proofs are not built on a vacuum; proof teaching that is not carried out in accordance with mathematical understanding causes difficulties to the students. A lack of mathematical knowledge make proofs quite incomprehensible. The fact that students focus on operations rather than on content while performing proofs makes it difficult for them to do proofs (Baker, 1996).

In order to face the students difficulties, mathematics teaching should promote, following curricular and social demands, students' relational understanding (Skemp, 1978), and avoid that students learn definitions and theorems by memorizing proofs without understanding them (Cadwallader-Olsker, 2007). Harel and Sowder (2003) conducted a study at the university level that reported good outcomes in making proofs clear, convincing and understandable for students. The teaching experiment designed in this study was based on teaching proofs in a way that enabled sense-making.

A revision of the research literature provided us studies on students' proof levels according to various taxonomies. Studies conducted with prospective mathematics teachers have reported that most of them have empirical proof schemes (Martin \& Harel, 1989). Martin and Harel (1989) found that half of the prospective mathematics teachers were unable to complete a proof, and that those who were able to complete it had empirical proof schemes. Even students who had previously taken a course on proofs tried to complete a proof by memory since they did not understand how to do the proof (Moore, 1994). Housman and Porter's (2003) study of high-achieving students found that they had external conviction, empirical and deductive proof schemes. Hoyles (1997) asked primary and secondary school students to show that the interior angles of a triangle add up to $180^{\circ}$ and categorized their proof schemes as empirical, enactive, narrative and visual. Asking the same question, Oflaz, Bulut and Akçakın (2016) showed external conviction and empirical proof schemes. When asked about their perspectives regarding proofs, the students emphasized that it is necessary to teach lessons with proofs and added that they have difficulties understanding proofs since they lack sufficient experience with them. Moralı, Uğurel, Türnüklü and Yeşildere (2006) developed a study with prospective primary mathematics teachers and found that they did not find it necessary to use proofs in mathematics lessons. Schwarz et al. (2008) carried out a study of the proof abilities of prospective teachers in three different countries and determined that they were unable to construct mathematical proofs even though they were asked questions containing secondary-school content. The literature supports studies of students' proof processes and frameworks (Balacheff, 1988; van Dormolen, 1977; Weber, 2004).

Harel and Sowder (1998) focused on how students convince themselves about the correctness of an expression and categorized these processes as external conviction, empirical and deductive proof schemes. External conviction proof schemes depend on an authority such as a teacher or a book, on strictly the appearance of the arguments or on symbol manipulations. External conviction proof schemes are divided into authoritative, ritual and symbolic. Empirical proof schemes are based either on evidence obtained directly from quantitative measurement samples, on the basis of algebraic expressions, or on the substitution of certain numbers in perceptions. Inductive and perceptual proof schemes are in this class. In the deductive proof scheme, deductions are made from certain axiom sets. The deductive proof scheme consists of two subcategories, each consisting of various proof schemes: the transformational and the axiomatic proof schemes. In this study, the prospective teachers' processes of proving were categorized using the proof schemes of Harel and Sowder (1998).

\subsection{The Need for International Comparative Research on Proving}

Studies of the mathematical performance of students from different countries have grabbed attention in recent years. At the same time, different practices and approaches are being studied with an international approach in mathematics education studies. This has led researchers to focus on differences. Determining the reasons for these differences by investigating them constitutes the subject of comparative studies (Artigue \& Winsløw, 2010). Some comparative studies focus on the mutual benefits of shared good practices or the applicability of policies and practices of other nations' educational systems (Clarke, 2003). Most comparative studies are carried out in two ways: large-scale comparative studies using quantitative methods and small-scale qualitative studies (Andrews, 2007; Xsenofontos, 2010). 
In this study, the prospective teachers' proof schemes were determined and compared, and the results were evaluated using a mixed approach (predominantly qualitative). For this purpose, the sub-problems of this study were determined as follows:

1. What are the proof schemes of prospective mathematics teachers at a state university in Turkey?

2. What are the proof schemes of prospective mathematics teachers at a state university in Spain?

3. Are there differences in the proof schemes of prospective mathematics teachers at the state universities in both countries?

\section{Method}

\subsection{Design of the Study}

This is a case study, a very common qualitative study design. Case studies are an in-depth description and investigation of a limited system (Meriam, 2013, p. 40).

\subsection{Participants}

51 prospective primary teachers at their second year of their degree in the Faculty of Education of the University of Huelva (Spain) and 45 junior prospective teachers from the department of mathematics education at Cumhuriyet University in Turkey participated in this study. The implementation was carried out in May (Spain) and in October (Turkey) 2017.

A purposeful sampling technique was used to select the participants to be interviewed at the end of the implementation. The responses of the prospective teachers were categorized using the proof schemes of Harel and Sowder (1998), and one prospective teacher was selected as an example for each scheme in each country to be interviewed.

\subsection{Data Collection and Analysis}

After a review of the research literature on proof schemes, a Proof Test (PT) consisting of four questions about proofs for parallelograms was developed (Figure 1). This PT was delivered to four prospective primary mathematics teachers in both countries in order to check time completion and understandability, resulting that the questions were comprehensible and the need of approximately 45 minutes to do the test. Therefore, the implementation was carried out in one lesson hour at both universities. The responses were categorized by two researchers applying Harel and Sowder's (1998) taxonomy of proof schemes using descriptive analysis.

\begin{tabular}{l} 
1. Prove that $|B E|=|E F|=|F D|$ \\
2. Prove that $|A C|^{2}+|B D|^{2}=2\left(|A D|^{2}+|A B|^{2}\right)$ \\
4. Prove that $|A F|=|F C|$ and $|D F|=|F B|$ \\
\hline
\end{tabular}

Figure 1. Four Questions About Proofs For Parallelograms 
The analyses of two experts were compared, the dissimilar results were discussed, and a consensus was reached on the results. Based on these analyses, three prospective teachers from each country were interviewed one week after the implementation. These semi-structured interviews were video-recorded and transcribed, and analyzed using Harel and Sowder's taxonomy. In the interviews, which lasted about 50 minutes, the prospective teachers were given their PTs again and asked to explain how and why they did their proofs. The results of this analysis allowed us to go onto the comparative analysis.

\section{Findings}

A detailed analysis of the prospective teachers' work selected from Turkey and Spain samples are presented. Then, the proof schemes of the prospective teachers in the samples of both countries are compared.

\subsection{Findings for the Proof Schemes of the Prospective Teachers in Turkey Sample}

One presents the proof schemes, which were determined according to the findings of the first implementation in Turkey sample, and a detailed analysis of the works of the three selected prospective teachers.

The proof schemes in Turkey sample are presented in Table 1 . The majority of the Turkish prospective teachers were either unable to solve the proof or did an incomplete proof. In addition, the prospective teachers concentrated on the ritual and transformational schemes. Only 6 solved Proof 1 using the external conviction scheme, and the remaining 39 either could not solve the proof or gave an incomplete answer. The authoritarian proof scheme was only encountered in Proof 1. For Proof 2, 11 prospective teachers had the ritual proof scheme and 6 had the transformational proof scheme. 15 prospective teachers were not able to answer at all, while 7 gave irrelevant answers. The prospective teachers mostly had the transformational and ritual proof schemes for Proof 3 , and the perceptual proof scheme was only encountered in this proof. The transformational proof scheme was similarly the most common scheme in Proof 4 , while 10 prospective teachers had the symbolic proof scheme among the external conviction schemes. In this proof is where one finds more answers by the prospective teachers. No prospective teachers had the axiomatic proof scheme.

Table 1. Proof Schemes of The Prospective Teachers In Turkey Sample

\begin{tabular}{|c|c|c|c|c|c|}
\hline \multicolumn{2}{|c|}{ Proof schemes } & Proof 1 & Proof 2 & Proof 3 & Proof 4 \\
\hline & Authoritarian & 2 & & & \\
\hline & Ritual & 2 & 11 & 7 & 5 \\
\hline & Symbolic & 2 & 2 & 1 & 10 \\
\hline & Perceptual & & & 3 & \\
\hline & Inductive & & 4 & 1 & 3 \\
\hline & Transformational & & 6 & 11 & 11 \\
\hline \multicolumn{6}{|c|}{ Axiomatic } \\
\hline \multirow{2}{*}{ 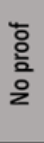 } & Nothing & 20 & 15 & 13 & 12 \\
\hline & $\begin{array}{l}\text { Manipulation of data } \\
\text { without any } \\
\text { consciences of proof } \\
\text { apparently }\end{array}$ & 19 & 7 & 9 & 4 \\
\hline
\end{tabular}

3.1.1 Findings of the Detailed Analysis of the Works of Three Prospective Teachers Who were Selected from Turkey Sample

\subsubsection{Su's Proof Schemes}

$\mathrm{Su}$, whose explanations were insufficient in the first implementation, was considered in the category of external conviction. Su considers herself a math lover and a talented math student. She does not want to be a teacher in the future, but want to work in the field of mathematics. 


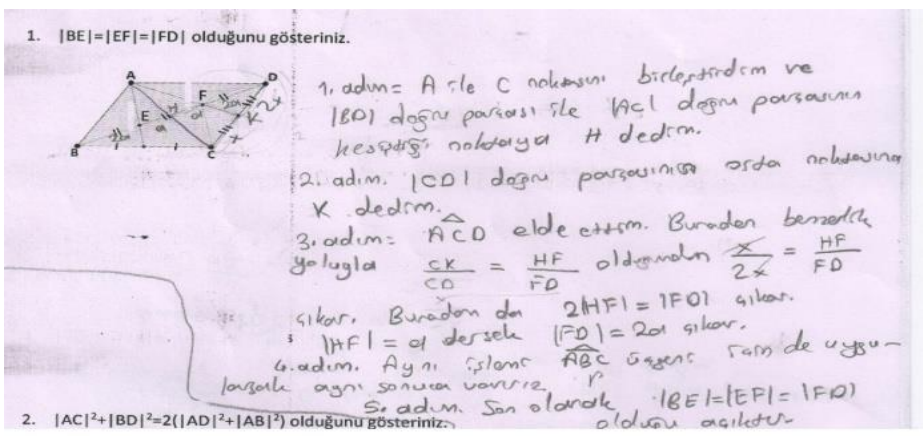

Figure 2. Su's Worksheet $\left(1^{\text {st }}\right.$ question $)$

Su's worksheet in the first implementation shows that she was trying to reach a conclusion by establishing a similarity between the sides of ACD triangle that was formed by combining the A and C points in the first question (Figure 2). Thus, Su was trying to reach a conclusion by establishing a similarity between random sides not based on logical evidence. In the interview, after thinking of what to do, it came to Su's mind to look at the similarity. In order to find a similarity, she said that she needed "the ratio of that to that, the ratio of this to this." Similar to the operations carried out in the first implementation, she tried to find a similarity among random sides instead of finding similar triangles and expressing the similarity among the sides lengths of these triangles.

$\mathrm{R}$ (Researcher): What was the similarity?

$\mathrm{S}(\mathrm{Su})$ : I cannot say ... The similarity is that the ratios of the sides are equal to each other...

$\mathrm{R}$ : In the first implementation, you found a similarity among irrelevant sides. I wonder you wrote this because you think which triangles are similar?

S: Maybe there was no similarity. I might have done so in order to adapt to the question. I might have done it so as to be equal.

Su tried to find a similarity among random sides with completely random operations. In order to reach a result somehow, she noted similarities among irrelevant sides without knowing much about the meaning of the concept of similarity. Then, she investigated the angles in the parallelogram by saying "Shall we proceed from angles?" With a hope of finding a similarity, she looked for equal angles and asked the researcher whether the angles ABC and $\mathrm{ADC}$ are equal. The fact that Su asked the researcher without knowing that these angles are congruent. So it can be interpreted as having incomplete knowledge of this topic. Later, she reached a conclusion by forming a similarity between the correct triangles, with the researcher's guidance.

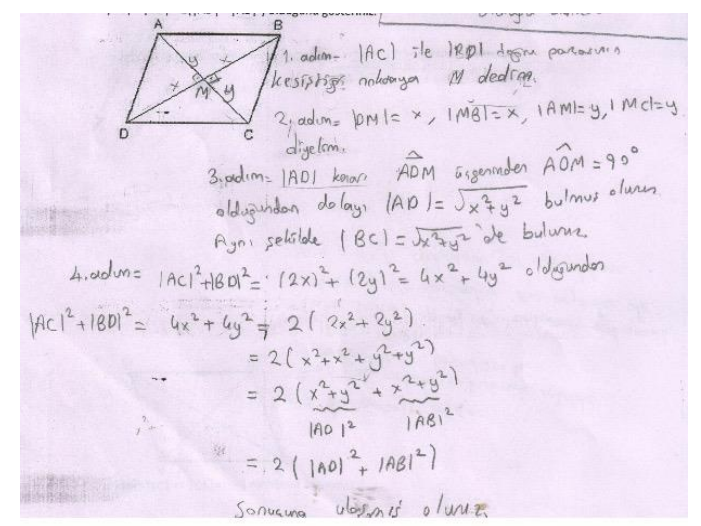

Figure 3. Su's Worksheet (2nd question)

For the second question, Su carried out operations with an incorrect assumption that she assumed to be correct from the beginning. Thus, Su examined the ADM and BCM triangles formed by giving the name $\mathrm{M}$ to the intersection of diagonals. She applied the Pythagorean theorem to these triangles with an assumption that the $\widehat{A M D}$ and $\widehat{B C M}$ were 90 o. Using the equations among the sides obtained according to the Pythagorean theorem, she tried to show the correctness of her assumption by substituting these equations with the assumption given in 
the question (Figure 3).

In the interview, Su thought to reach a conclusion using a formula.

S: Can we benefit from the formula and so forth?

R: Which formula?

$\mathrm{S}$ : Was there the sine formula or was there?

$\mathrm{R}$ : What is the sine formula?

S: I do not know, something like that remained in my mind, but I don't remember what formula was that...mmm...What can we do? Would it be right to write using equations (given in the question) to show this equation (given in the question) and to say that it was provided? Would I divide two sides by 2 ? That is to say, would I write this, do a few operations, say that it is equal, in order to show that this equation is true?

R: In a sense, by substituting values?

S: No, it is not substituting values, let me try...

$\mathrm{Su}$ thought of using the sine formula without remembering the formula, even without being sure of the existence of such a formula. This situation indicated that without thinking whether it is useful to reach the conclusion, $\mathrm{Su}$ listed the formula names that came to her mind about triangles and acted according to the researcher's reactions. Additionally, saying "Would I do a few operations, and say that it is equal?" meant that Su had a tendency to reach the conclusion using random operations rather than showing that the equation is true by doing operations according to the triangle properties.

R: In your first worksheet, you expressed the intersection of the diagonals as $90^{\circ}$. Do you think it is $90^{\circ}$ ?

S: It does not look like $90^{\circ}$. Besides, I cannot know if it is $90^{\circ}$. It could be...

R: Could it be?

S: Can it not be? Would it be a square if it is?

As well as not being sure that the opposite angles of a parallelogram are congruent, Su thinks that diagonals bisect each other at right angles. Later, she added that the angles did not look like right angles based on the visual property of the shape. This reminds us the visualization level, the lowest of van Hiele's levels of geometric thinking. Even though Su is not at the visualization level, the fact that she made a judgment based on shape properties for this question can be inferred to mean that she lacks knowledge about this topic. Later, with the researcher's guidance, she reached the conclusion doing some random operations, drawing perpendiculars and using the Pythagorean theorem.

For the fourth question, she thought of applying the Pythagorean theorem by drawing an auxiliary element with her tendency, which she gained in the other questions, to avoid determining which operations would lead the solution.

S: I generally tried to reach the solution by assuming the equation given is true. Would I make somewhere $90^{\circ}$ (drawing a perpendicular from the vertex D to the diagonal |AC|)?... I need to find something that is both $90^{\circ}$ and has the angle $a$ in order to figure out the ratios. That DFC angle is $(180-a)$, I shall consider the cosine, sine of the ratio. I shall draw a perpendicular from somewhere.

$\mathrm{R}$ : There are four triangles. For example, how do you find the area of the FDC triangle.

$\mathrm{S}$ : With the sine formula.

$\mathrm{R}$ : What is sine formula?

Su has some knowledge, even though it is incomplete and inaccurate, based on her experiences in education. Her idea of using the sine formula to find the area of a triangle with one angle measurement given might indicates this. After the researcher reminded her of the area formula with sine, Su was able to determine the area of the triangle correctly.

S: $A(D F C)=1 \div 2 \cdot|F C| .|F D| \cdot \sin (180-a) \cdot 180-a$ is the state of $a$ with a minus. That is to say, it will be sina with a minus. That is to say, I can express this as sina by putting a - before this expression.

R: Will the area not be negative in this case?

S: It should not be negative. But, the sina takes a value between -1 and 1 ; thus, the sina has a negative value.

$\mathrm{R}$ : Think of the coordinate system. In which quadrants, is sine positive? 
S: In two and three. In the first quadrants, they are all positive. Cosine is positive in the first and fourth quadrants, and sine is positive in the first and second quadrants. Okay, sorry, then, this expression is positive, not negative.

Su's incomplete and inaccurate knowledge manifests itself later on with this question. She made a mistake even on the topic of positivity and negativity of the sine and cosine functions in quadrants, which can be considered as the basis of the trigonometry topic. She was thought to lack a serious knowledge of this topic because she claimed that the value of $\sin (180-a)$ should be negative, which would cause the area to be negative.

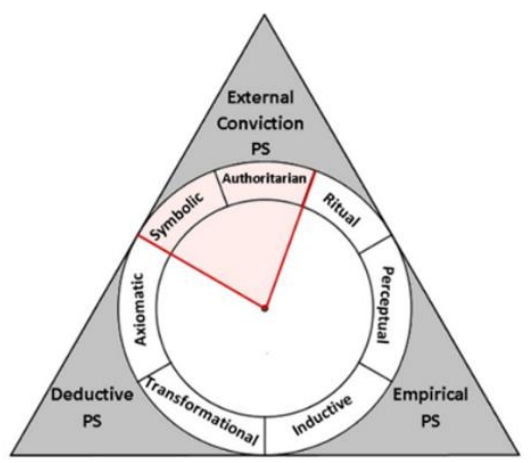

Figure 4. Su's Proof Scheme

The results of the interview showed that Su tried to reach the conclusion using random properties and formulas without knowing which operation would lead to the conclusion. For example, the fact that when she starts to solve a question, she attempts to solve this question in the way that she used to solve the previous question without thinking of the question itself might indicate this situation. Therefore, Su who has behaviors that are appropriate to the authoritarian and symbolic proof schemes, was deemed to have the external conviction proof scheme (Figure 4).

\subsubsection{Can's Proof Schemes}

Can who has a moderate level worksheet according to his operations in the first implementation was interviewed. He was deemed to have an empirical proof scheme based on the operations he carried out. He can reason mathematically, but he does not think of himself as successful in mathematics.

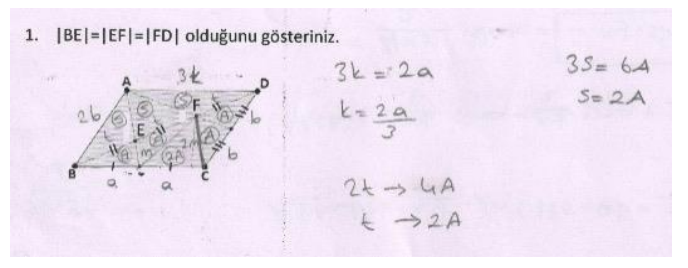

Figure 5. Can's Worksheet ( $1^{\text {st }}$ question $)$

When Can's worksheet was investigated, it was determined that he attempted to reach the conclusion using areas for the first question (Figure 5). His reason for this choice was: "We can use areas in this question because we used to do in high school." By relating to his previous experience, he thought that using areas would lead him to the correct conclusion for this question, too. Therefore, he started off using the side-area relations in triangles. However, he still accepted that his assumption was correct and completed the proof accordingly. As he did in the first implementation, he tried to reach the conclusion using the areas of triangles in the interview. With the researcher's guidance, he said:

$\mathrm{C}$ (Can): Using similarity, if this is $a$, there is the ratio of $1 / 2$ here, and this $(|\mathrm{AB}|$ length) becomes $2 a$ from the butterfly rule.

$\mathrm{R}$ (Researcher): Which triangles do you see as similar?

C: If I call G this point, DFG and AFB. In fact, the conclusion was directly reached from here. If I combine A and $\mathrm{C}$, and call it the center of gravity? (draws the $|\mathrm{AC}|$ diagonal). It becomes the center of gravity; yet, how can I say that? 
$\mathrm{R}$ : What was the center of gravity?

C: The center of gravity divides in the ratio of $1 / 2$ and the sides are congruent.

What the prospective teacher described as the butterfly rule is, in fact, the similarity rule in triangles. He tried to reach the conclusion using some knowledge. However, he tried to set all his knowledge and to use whatever might lead to a conclusion, rather than using the knowledge needed to complete the proof. For example, he calls the intersection of a median drawn from a vertex and any line drawn from another vertex to the opposite side as the center of gravity in an $\mathrm{ABC}$ triangle. The center of gravity, in fact, is the intersection of three medians in a triangle. This might indicate that Can has incomplete and inaccurate knowledge regarding the elements of triangles.

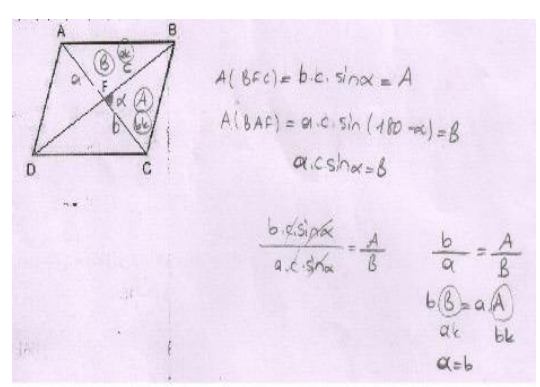

Figure 6. Can's Worksheet (3rd question)

When Can's answer to the third question was investigated, it was seen that he tried to reach the solution using the areas of triangles. He found the areas of BFC and BAF triangles by applying the sinus area formula. $\mathrm{He}$, later, found that the areas of the triangles are congruent by proportioning their areas. Based on the rule that the areas of triangles with the same heights are proportional to the lengths of their bases, he showed that the lengths of these triangles' bases are congruent since their areas are congruent (Figure 6).

Like his approach to other questions, he also completed this question considering the areas of triangles. Unlike his peers, his proof of the equality of the side lengths by relating it to the areas of triangles indicated that Can completed the solution using mathematical thinking process.

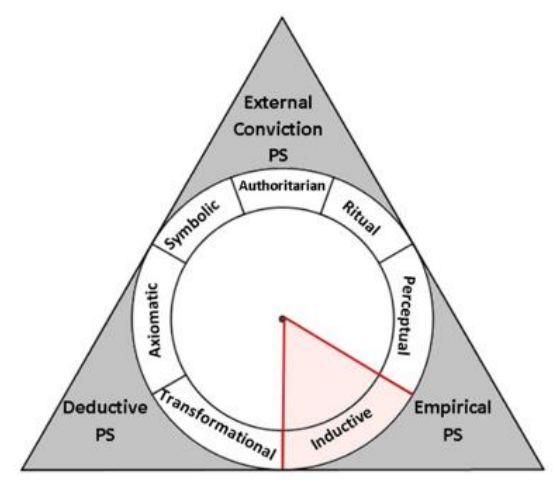

Figure 7. Can's Proof Scheme

His interview revealed that he tried to reach the solution using the areas of shapes in all of the questions because of his experience doing so in his previous education. However, he was able to reach the correct solution with the researcher's guidance even if he tried to solve each question in a similar way. Therefore, Can, who has deficiencies in some topics, can be said to have the empirical proof scheme (Figure 7).

\subsubsection{Nur's Proof Schemes}

When Nur's worksheet was investigated, it was determined that she was able to express the correctness of her assumptions. So, she has the empirical proof scheme. Nur is a prospective teacher who can reason correctly and express her ideas mathematically. 


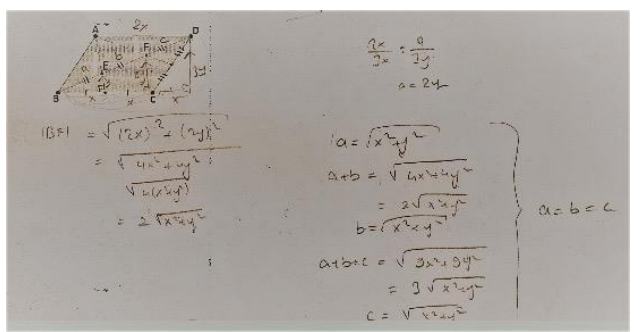

Figure 8. Nur's Worksheet ( $1^{\text {st }}$ question $)$

Nur's worksheet for the first implementation showed that she tried to reach the conclusion for the first question applying the Pythagorean theorem to the relevant triangles by drawing perpendiculars from the points of $\mathrm{E}, \mathrm{F}$, and $\mathrm{D}$ to the $|\mathrm{BC}|$ side. However, she made these mistakes: the perpendicular drawn from the point $\mathrm{E}$ coincided with the midpoint of the $|\mathrm{BC}|$ side, and the perpendicular drawn from the point $\mathrm{F}$ coincided with the point $\mathrm{C}$, and then she tried to reach a solution by accepting the assumption that was supposed to be proved and using the similarity rule (Figure 8).

In the interview, she similarly tried to show the correctness of the assumption by accepting it as true. Nur primarily denoted the lengths in the shape with letters. She tried to reach the conclusion somehow by applying the Pythagorean theorem to the triangles formed. Later, she tried to remember what she did in the first implementation and said that she wanted to solve this question later. In her second attempt, she started with indicating the congruent sides again by giving letter values to the sides.

$\mathrm{N}$ (Nur): If I draw a diagonal from $\mathrm{A}$ to $\mathrm{C}$, the lengths that this diagonal divides on $|\mathrm{BD}|$ will be equal... What could we reach from there? When I see a parallelogram, drawing a perpendicular comes to my mind. I draw a perpendicular line from there (the point $\mathrm{D}$ ) (to the $(|\mathrm{BC}|)$. However, I don't know whether I can reach the conclusion from there.

$\mathrm{R}$ (Researcher): If you think a bit more simply...

$\mathrm{N}$ : Will we use similarity again?

$\mathrm{R}$ : Focus on the ACD triangle if you like. Isn't $|\mathrm{AL}|$ a median?

$\mathrm{N}$ : Then, if we draw a line from $\mathrm{C}$ to $\mathrm{F}$, this also divides $|\mathrm{AD}|$ into two equal parts and becomes a median. Because if $|\mathrm{AL}|$ divides the side into two equal parts passing on the point $\mathrm{F}$, the line drawn from the other vertex (from the point $\mathrm{C}$ ) also divides $|\mathrm{AD}|$ into two equal parts.

$\mathrm{R}$ : Is it sufficient for $|\mathrm{AL}|$ to be a median in order to make this inference?

$\mathrm{N}$ : Hmm..The length of $|\mathrm{BD}|$ also divides $|\mathrm{AC}|$ into two equal parts. Therefore, the other one is a median since it passed on the point $\mathrm{F}$. Then, there was an $a / 2 a$ ratio in median (the ratio of $|\mathrm{FL}|$ to $|\mathrm{FL}|$ ). The ratio of $|\mathrm{OF}|$ to $|\mathrm{FD}|$ will be $1 / 2$. Similarly, the ratio of $|\mathrm{BE}|$ to $|\mathrm{EO}|$ in the other triangle (the $\mathrm{BAC}$ triangle) will be two. $|\mathrm{BO}|$ and $|\mathrm{OD}|$ were equal to each other from the parallelogram property. Therefore, $|\mathrm{EO}|$ and $|\mathrm{OF}|$ become equal to each other. That is to say, it becomes $|\mathrm{BE}|=|\mathrm{EF}|=|\mathrm{FD}|$.

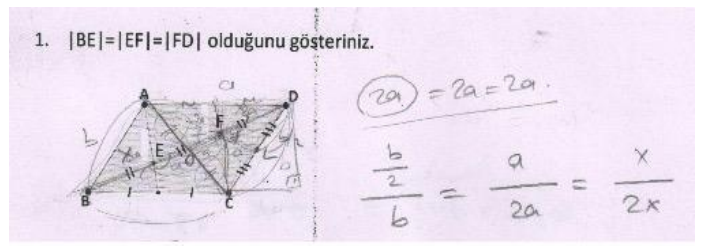

Figure 9. Nur's Worksheet (1st question, second attempt)

In her second attempt, Nur reached the conclusion using the auxiliary drawings (Figure 9). She again preferred to apply the Pythagorean theorem primarily by drawing a perpendicular from the point $\mathrm{D}$ to the side $|\mathrm{BC}|$. Then, with the researcher's direction, she focused on the ACD triangle by drawing the $|\mathrm{AC}|$ diagonal. She showed that the assumption given is correct by drawing medians of the sides of $|\mathrm{CD}|$ and $|\mathrm{AD}|$ and using the properties of medians. While nearly all the prospective teachers reached the conclusion by constructing similarities between triangles for the solution of this question, Nur additionally applied the properties of medians, indicating that she 
has a different point of view. For the third question, Nur found a solution by giving the same letter value to the congruent side lengths and angles and benefiting from the similarity of triangles on her worksheet for the first implementation. Therefore, she showed the correctness of the assumption by accepting it as true. In the interview, she started by indicating the equality of the interior alternate angles by primarily giving letter values to the equal lengths of the parallelogram.

$\mathrm{R}$ : What are you going to do?

$\mathrm{N}$ : I am trying to show why these equations are equal.

R: You have again accepted that equations given are correct. You're asked to show this.

$\mathrm{N}$ : I found it from the $\mathrm{Z}$ rule. That is to say, from the properties of parallelograms.

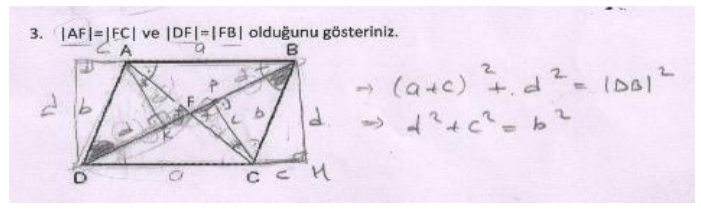

Figure 10. Nur's Worksheet ( $3^{\text {rd }}$ question)

What Nur called the $\mathrm{Z}$ rule is the rule of the equality of the interior alternate angles in triangles. As Nur got in the habit of accepting that the assumption given is true, she chose to give letter values to the congruent lengths. Later, she tried to apply the Pythagorean theorem by drawing perpendiculars from the points of B and D to the opposite sides (Figure 10).

$\mathrm{R}$ : What are you trying to see?

$\mathrm{N}$ : In fact, we need to draw a perpendicular there in order to see (she drew perpendiculars from the point A to $|\mathrm{DB}|$ and from the point $\mathrm{C}$ to $|\mathrm{BD}|)$.

R: What do you see now?

$\mathrm{N}$ : From here (meaning the CFBH quadrilateral) this $(|\mathrm{BH}|$ and the distance between the point $\mathrm{B}$ and the point where the perpendicular intersects the side) is $d$, I suppose, I remember it like this. Those perpendiculars are equal to each other, $c$. This $(|\mathrm{BC}|)$ is already $b$.

$\mathrm{R}$ : Why are the perpendiculars equal to each other?

$\mathrm{N}$ : I don't know why, but I remember it like this. It was stuck in my mind like this.

R: But you are not sure, you just remember it like this.

$\mathrm{N}$ : I start the process from here. Let me see whether they will be equal. Later, I will think of why it is so.

$\mathrm{R}$ : Look at the AFD and FBC triangles...

$\mathrm{N}$ : Those (the AFD and BFC angles) are alternate interior angles. There is a similarity between the AKF and FCP triangles. For this reason, the sides that the angles face will be congruent. Because they are congruent triangles. The angles are equal to each other, and the perpendiculars are equal to each other. In this case, $|\mathrm{AF}|$ will also be equal to $|\mathrm{FC}| .|\mathrm{DK}|$ and $|\mathrm{PB}|$ are already equal to each other. Therefore, $|\mathrm{DF}|$ and $|\mathrm{FB}|$ are equal to each other.

Nur found a similarity between the AKF and FPC triangles and a similarity ratio of 1 since the length $|\mathrm{AF}|$ is equal to the length $|\mathrm{FC}|$. In this case, as well, she did the proof by accepting the assumption. Nur's result that the other sides are congruent considering the fact that the lengths of the perpendicular sides are congruent is, in fact, the result that can be obtained after showing the lengths of the $|\mathrm{AF}|$ and $|\mathrm{FC}|$ sides are equal to each other.

As a general evaluation, Nur prefers to apply the Pythagorean theorem by drawing a perpendicular from one point to a side for such questions. This indicates that as she gotten into the habit of drawing auxiliary elements and applying the rules that she knows, she tried to reach the conclusion somehow rather than carrying out operations to solve the question that was asked. 


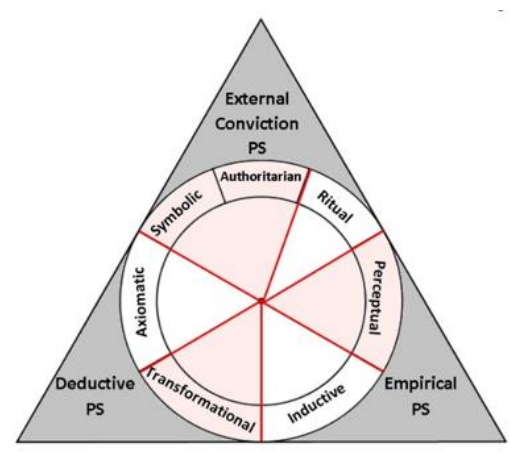

Figure 11. Nur's Proof Scheme

Instead of reasoning by making inferences, Nur tended to prove the assumption by initially accepting that the assumption was correct and applying a set of operations. Therefore, her operations were not very suited to the purpose. Based on her operations, it can be said that she has the empirical proof scheme (Figure 11). Proving can be done in more than one way (Raman, 2003). Harel and Sowder (1998) argue that one can't prove that there is a single proof of proving that the same question can be proved by using different proof schemes. So Nur does not exhibit only one proof scheme, she exhibits more, three of the proof schemes at the same time.

\subsection{Results for the Proof Schemes of the Prospective Teachers in Spain Sample}

The proof schemes of the prospective teachers in Spain sample are presented in Table 2. The majority of Spanish prospective teachers are unable to perform any proof. An average of almost the half of the group make nothing in some of the proofs. The most frequent proof schemes have been the symbolic and the inductive. It is interesting to note that 22 prospective students did nothing in Proof 1 while 9 used the empirical scheme and 7 used an external conviction scheme in this case. In Proof 2, 22 participants used an inductive scheme while 3 used a symbolic scheme and 12 did nothing. This was the proof that more students could solve. For Proof 3,17 prospective teachers used an empirical scheme, 9 solved this proof using an inductive scheme and 8 using a perceptual scheme, what make this the case that most people used a perceptual scheme. In addition, 7 solved the proof using external conviction schemes, 5 of them using symbolic scheme. Finally, 14 prospective teachers solved Proof 4 using an external conviction scheme, concretely 13 out of them used symbolic reasoning. On the other hand, 17 prospective teachers did nothing in this case. It is important to mention that no prospective teacher solved any proof using deductive schemes or the authoritarian scheme.

Table 2. Proof Schemes of the Prospective Teachers in Spain Sample

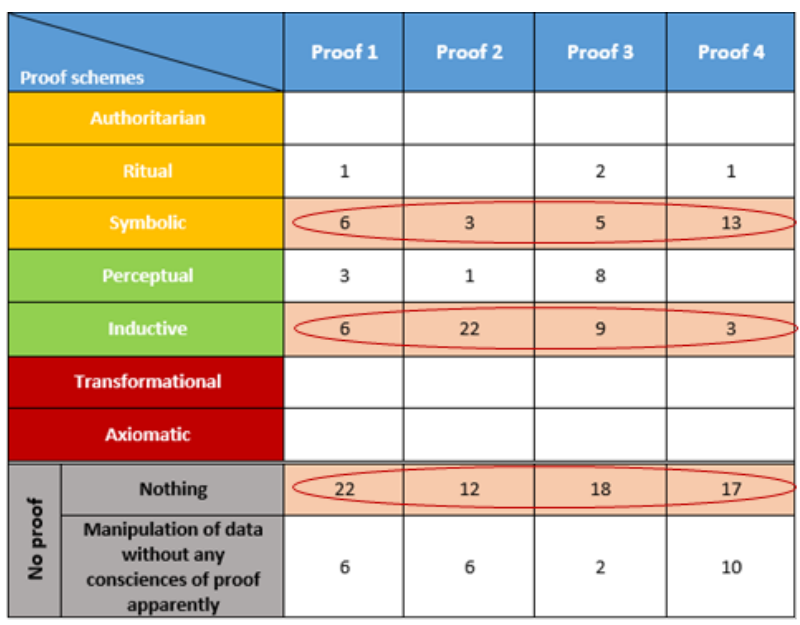

3.2.1 Results of the Detailed Analysis of the Works of Three Prospective Teachers Who Were Selected from Spain Sample

\subsubsection{Daniel's Proof Schemes}

Daniel said that he got average marks in Maths in Secondary Education, also he claims that he used to show no 
interest in Maths. However, he said that his motivation about Maths increased at the university, improving his marks. On the other hand, it is interesting to say that he studied Technical Drawing at high school so he believes that this is the reason he likes Geometry.

Daniel tried three of the four proofs. We focus on the first proof because this was the most developed and it's possible to clearly perceive what proof scheme he shows. It's important to mention that three resolutions have a common reasoning: it is the initial transformation of the original shape in a well-known shape for him. Daniel studies the properties of the original shape using a rectangle in the three and fourth proofs. In the first proof, he decomposes the rhomboid in two triangles by the minor diagonal because he knows the triangle properties better.

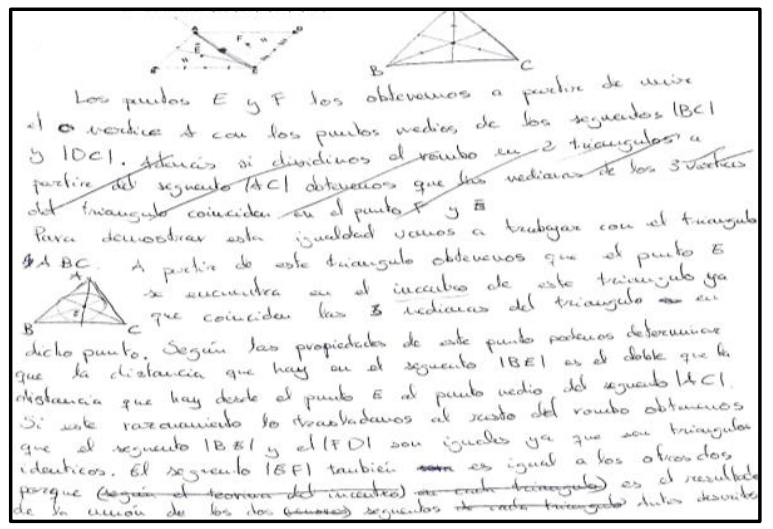

Figure 12. Daniel's Worksheet (1st question)

Daniel notices the medians of the triangles $\mathrm{ABC}$ and $\mathrm{ADC}$ in which the rhomboid is discomposed and uses a well-known property of the barycentre, though he called, wrongly, incenter (Figure 12). He used the property that the distance between one vertex of the triangle and the barycentre is twice the distance between this point and the midpoint of the opposite side. Daniel claims that he could proof this result thanks this property that he remembers from the Technical Drawing lessons at high school. However, he makes some conjectures without a logical explanation. We realize it when he says that the segment composed by the vertex B and the intersection of the two diagonals of the rhomboid, which we name as M onwards, is a median.

D (Daniel): [...] actually we need two medians to find out the barycentre. Then, I was thinking that these two triangles are equal; if we connect the vertex of one with the vertex of the other one (he means vertices B and D), as they share a side, I thought that it would be the midpoint $(\mathrm{M})$. In this way, we have the median determined by the vertex $\mathrm{A}$ and the midpoint of the side $\mathrm{BC}$. On the other hand, we have the median from the vertex $\mathrm{B}$ until the midpoint of AC.

$\mathrm{R}$ : Why did you say that this point (vertex M) is the midpoint of AC and BM is a median?

D: I suppose this because I thought that I need to use the median to solve the problem [...]. I thought that I had to adapt the shape to make sense. Because if I don't suppose that $\mathrm{M}$ is the centre I don't know how to continue the proof. I couldn't continue my strategy. Then I said to myself, "I have to suppose it" to solve the proof.

He used a similar reasoning when he justifies that both triangles in this rhomboid are equal.

$\mathrm{R}$ : Was there some idea that made you think that these triangles are equal?

D: Mm... I think that I only observed the symmetry of the picture. As it is said that these and these sides are equal (he means the sides BC and CD that appear in the picture that are equal), then two equal sides are... I don't know how to explain it.

We could notice that not every steps in this proof, that Daniel did, are consistent. Concretely, in the second paragraph, the prospective teacher uses reasoning based on a rudimentary mental image because he said that both triangles are equal based on the symmetry of the original shape. He does not use the properties of a parallelogram.

Furthermore, Daniel considers that his reasoning is valid for every kind of rhomboid. However, he is insecure in the case of other type of parallelograms. The prospective teacher said that he would need to check the figure in that case. This happens when Daniel had to prove the same property in a square. He tried to prove it in a superficial way, making drawings and applying the same lack of logic assumptions before mentioned.

On the other hand, it is important to highlight the explanation of Daniel when he tried to justify the absence of 
examples in his proof:

R: Why you did not use examples in your proof?

D: Aha, now I think that it would be logical to use them. I tried to prove it as mathematically as I could. I think that examples limit you to concrete cases. When we had to prove something, we had to prove in such a way that can be applied to all cases, that could be generalised.

$\mathrm{R}$ : What do you mean when you said that now it could be logical?

D: Because if I am not sure about any reasoning, I use an example to check if something is true. It's a previous step when you need to make generalizations [...].

R: So, why did you not use them then?

Daniel: Maybe, it was because I considered the proof as something more theoretical, then I did not think of using examples.

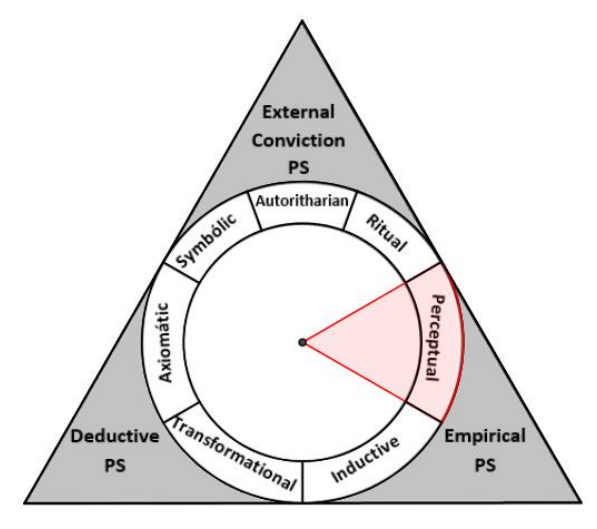

Figure 13. Daniel's Proof Scheme

This explanation places Daniel outside the inductive proof scheme, because although he recognizes the usefulness of using examples to understand a problem, he identifies the limitations of following an inductive process. However, we can observe that the reasoning followed is characterized by the connection of previous hypotheses, the results based on rudimentary mental images, the lack of logical arguments and the use of drawings to convince oneself and persuade others about the reasoning followed. These are singularities typical of the perceptual test scheme, so it can be said that Daniel has this proof scheme (Figure 13).

Finally, Daniel highlights the importance of teaching the notions of proof in mathematics classes. He said that this could improve the comprehension of results and mathematical properties in different areas. Also, he considers the introduction of abstract proofs in the curriculum at younger ages, trying to avoid the difficulties they cause beforehand.

\subsubsection{Monica's Proof Schemes}

Monica is a prospective teacher who had many difficulties with Maths in Secondary, even she claims hating them. However, her interest and participation in math classes increased at high school and at university, where she is studying the degree of Primary Teacher Education, after receiving private classes of mathematics in an academy during several courses.

In this case, the four proofs have been done following the same initial reasoning in each one, the decomposition of the original shape into triangles. As Monica claims, this strategy allows her to work with known properties on the triangle, instead of working with properties of the original parallelogram, which she does not know.

Focusing on the analysis of the different proof schemes that Monica shows, it is worth highlighting the response she offers when is asked in the interview about having worked a proof or activity similar to the fourth activity.

M (Monica): Let me think ... I sometimes help my cousin in private classes (7th grade) and, for example, he studies the basics of geometry [...]. In some activities they put a shape that joins a triangle with a square together, and say "find the area of the shape". You have to explain to the child that first he has to deal with the triangle and then with the square. Then you sum them and so on... 


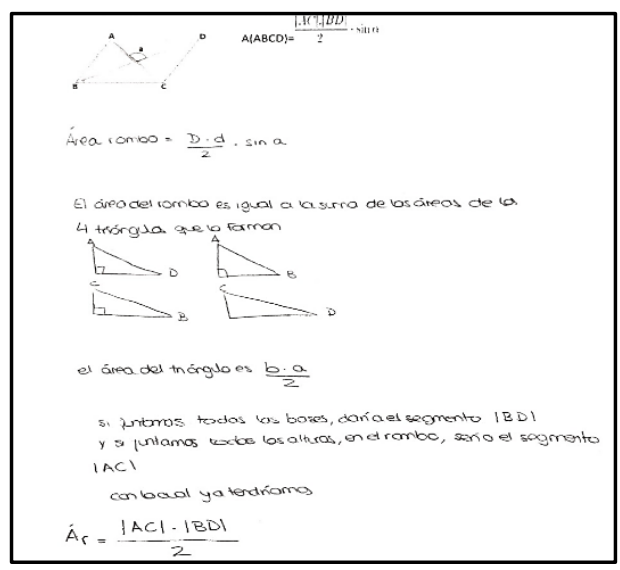

Figure 14. Monica's Worksheet ( $4^{\text {th }}$ question)

This is the idea that she shows in the first resolution. Monica tries to get the formula of the area of the rhomboid indicated in the statement from the area of the four triangles that composed the parallelogram, in the way that its semi diagonals constitute two of the sides of these triangles (Figure 14). However, this reasoning leads to a different result. She gets the formula of the area of a rhomb, as a consequence after having decomposed the rhomboid into four right triangles. Mónica does not realize it and considers that her proof is valid although incomplete, because she considers that she was unable to construct the formula indicated in which the sine appears. She claims that this is due to her lack of knowledge about trigonometry.

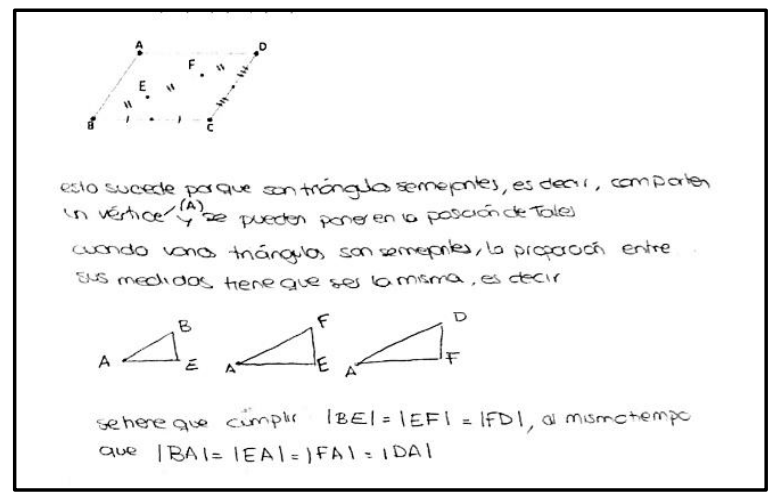

Figure 15. Monica's Worksheet ( $1^{\text {st }}$ question)

Something similar happens in the resolution of the first proof. In this case, Monica believes that she has correctly performed the proof based on the proportionality of the triangles that composed the rhomboid. He argues that triangles $\triangle \mathrm{ABE}, \triangle \mathrm{AFE}$ and $\triangle \mathrm{ADF}$ can be put in Thales position, because their sides are proportional and share the same vertex (Figure 15).

In the resolution of this proof, Monica remembers the type of exercises of similarity of triangles that she used to work in secondary, as she says:

R: Did you have something in your mind when you performed the proof in this way?"

M: "Honestly, I had the typical Secondary problem of ... I have a tree with such a height and here I have a girl. How tall is the girl? and it gives you the height of the tree.

R: Did you think you could put the triangles in that way due to your memories?

M: Exactly

In both fragments it can be seen how Monica presents limitations in her arguments, which are based on the search for a proving process similar to another that she knows. In addition, when considering the arguments, he has followed in each proof, we could say that her reasoning is influenced by the appearance of what constitutes a mathematical proof instead of worrying about the validity of such arguments. These aspects reflect a ritual proof 
scheme in Monica.

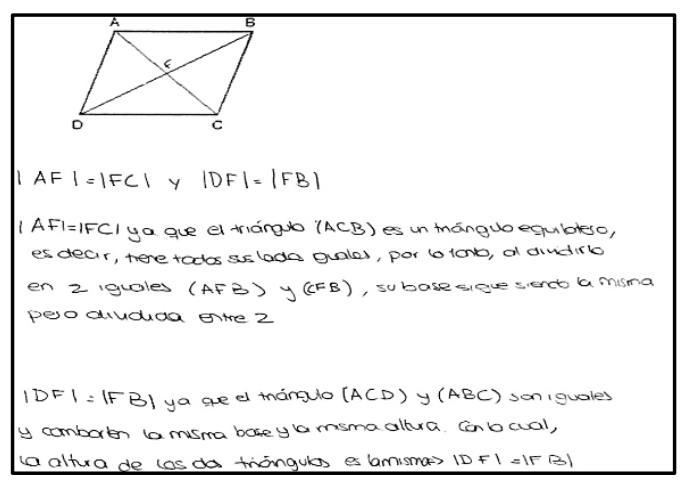

Figure 16. Monica's Worksheet (3rd question)

On the other hand, the reasoning that Monica follows in the third resolution is based on a rudimentary mental image. So, she shows a perceptual proof scheme also. In this case, the prospective teacher considers that the rhomboid could be divided into two equilateral triangles from its minor diagonal, considering that all its sides are equal to this diagonal (Figure 16). Mónica says that these triangles, in which the rhomboid is divided, are equal because, if you draw the parallelogram on a paper and fold it by its smaller diagonal, the triangles would overlap.

$\mathrm{R}$ : Why did you think that thistriangles are the same?

M: I saw that they were the same if I folded the figure on paper around here (she means to the minor diagonal) and the sides, I saw at first glance that they are the same. [...] This is true, I know it. Now I'm going to try to show the result.

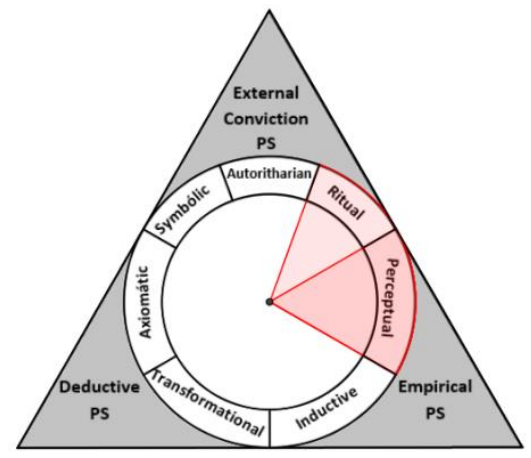

Figure 17. Monica's Proof Scheme

In addition, like Daniel, Monica also identifies the limitations of the proof process based on examples. She considers that having worked with examples would not prove the result, but an application of it. She recognizes the usefulness of using examples only as a method of checking a result. Therefore, Monica does not manifest an inductive proof scheme and based on his reasoning it can be said that she has the ritual and perceptual proof scheme (Figure 17).

Regarding her opinion about the teaching of the notions of proof in the mathematics classes, Monica considers that this knowledge constitutes only one of the parts of mathematics and that should not receive more attention than other areas that she considers more relevant, such as arithmetic or algebra.

\subsubsection{Marta's Proof Schemes}

Finally, we show the case of Marta, a prospective teacher, who expresses being "enchanted with mathematics" and having obtained excellent marks throughout her academic training. However, she also claims to have trouble when working with mathematical proofs, especially with geometrical ones.

Like Monica, Marta has done the four proofs presented. However, the initial reasoning that shares all the resolutions is different in this case. Marta makes measurements with a rule to the main elements of the 
parallelogram shown in each activity. As she expressed in the fourth activity, Marta uses this strategy to substitute numerical values in the given formula, trying to find a value of the area of the shape and then get conclusions (Figure 18).

M (Marta): I have taken measures with the rule and I have solved it by substituting the values in the formula. Then, after sine, what we have is a divided by b; hence I wrote nothing, as if that was something more general, I think.

R: What have you understood that you must prove?

M: That the equality is fulfilled. What I try to do is to introduce values in the formula to get the area ... Although now I think also that if I knew another way to calculate the area of the shape and matched the number I get from the formula, then I would have proven it.

R: So, what do you think must be proven in the activity?

M: That the two equalities give the same result.

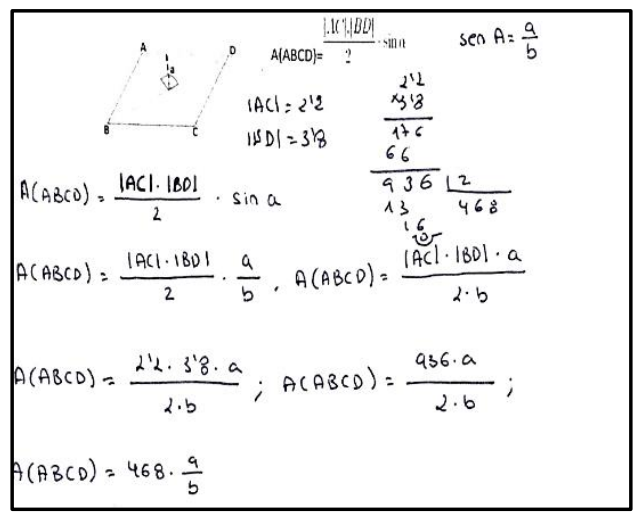

Figure 18. Marta's Worksheet $\left(4^{\text {th }}\right.$ question)

We observe that the initial reasoning followed by Marta is characterized by the approximation of the solution without having understood, first of all, what is intended to be proven. In this case, the prospective teacher performs the proof manipulating symbolic expressions without giving them a meaning. In the interview, she realizes the mistakes of understanding that she has made in her written resolution as it was showed in the previous fragment. Mentioned aspects of her reasoning are typical of the symbolic proof scheme.

In the same way, Marta shows a symbolic reasoning in the first proof. She uses the Pythagorean Theorem improperly in order to manipulate the expressions, which shows some incoherence in her reasoning (Figure 19).

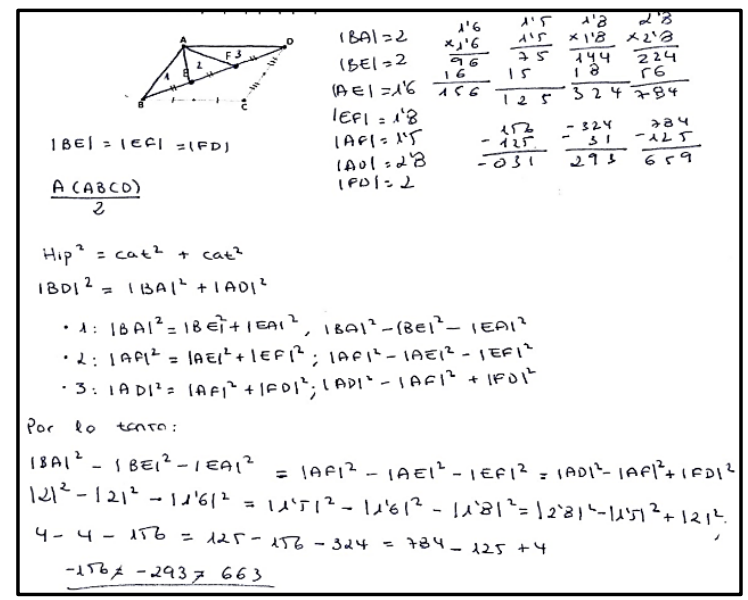

Figure 19. Marta's Worksheet ( $1^{\text {st }}$ question)

Moreover, we notice that Marta's reasoning shows aspects of the inductive proof scheme. In every proof, Marta 
shows a similar reasoning about the use of examples. The prospective teacher distinguishes theoretically in the interview that the way in which a result is usually generalized, is through algebraic language.

R: Do you always deal with numerical values when you carry out a proof?

M: No, you can also use letters [...]

$\mathrm{R}$ : In your case, how do you usually solve proofs?

M: I usually do first with numbers and examples; and then, I generalize with letters.

However, it was enough for her to obtain the result with a numerical example of each question, specifically the one obtained from the empirical measurements of the parallelogram, in order to generalize the result and conclude the proof. This conclusion was confirmed in the interview, despite having made the comment presented in the previous fragment.

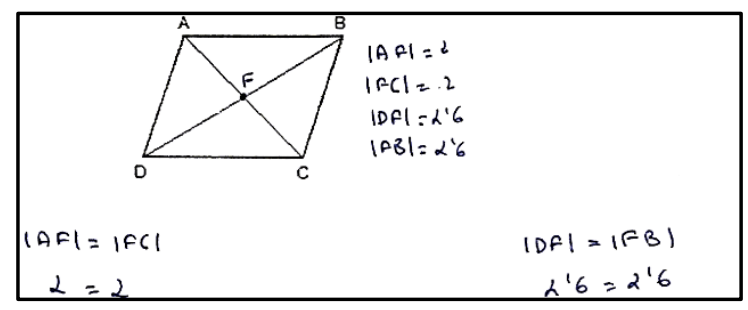

Figure 20. Marta's Worksheet ( $3^{\text {rd }}$ question)

For example, this type of reasoning can be observed in the third question, where Marta obtains the measurements of the semidiagonal of the rhomboid with a ruler. When she observes that they coincided, she considers that these segments are equal and, then, that she has been able to prove the result (Figure 20).

$\mathrm{R}$ : What do you understand by proving?

M: When the equality is true... If an equality is given to you and you want to prove it, the issue is that you have to prove that this equality is fulfilled.

$\mathrm{R}$ : Is it true in this case (original shape) or in any case?

M: I think that in this case, for this one (it refers to the rhomboid presented in the fourth question). Although I think it could be generalized too.

$\mathrm{R}$ : And do you think you have performed a valid proof in this question?

M: Yes.

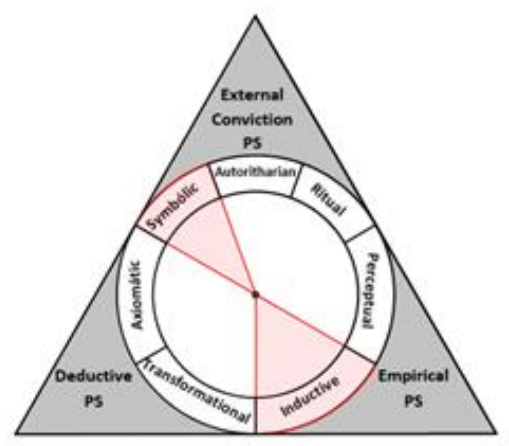

Figure 21. Marta's Proof Scheme

Based on this reasoning it is possible to say that Marta has the symbolic and inductive proof schemes (Figure 21).

Regarding her point of view about the teaching of the notions of proof in math classes, Marta, like Monica, considers the notions of proof as another part of mathematics that does not deserve special attention. She even expresses that this knowledge is not useful in most cases, because students could memorize the formulas without needing to understand their proof. 


\section{Discussion}

The majority of the prospective mathematics teachers (in Turkey and in Spain) were either unable to complete the proof or completed the proof in an inaccurate way, and, amongst those who completed the proofs, none used the axiomatic proof scheme, which is consistent with Schwarz and Kaiser (2009), who studied professional knowledge in several areas and countries, resulting that the future teachers could not construct formal proofs. According to van Hiele (1986), geometric thinking progress through levels. Students will be able to study on axiomatic system once they have reached the upper levels (Battista \& Clements, 1995). Prospective teachers may have lower geometric thinking levels to study on axiomatic systems. The authoritarian proof scheme was used by 2 Turkish prospective teachers only. If one compares this little use of this scheme with the amount of prospective teachers who do not complete the proofs, one can infer that an external authority is generally not considered as a plausible way to prove. As a global picture, Turkish schemes are dominated by external conviction and deductive schemes, and Spanish are dominated by empirical and external conviction schemes. A plausible reason is the scarce weight of deductive reasoning in Spanish schools at all levels.

Prospective teachers may have often used external proof schemes because they can't explain the problems according to their lack of knowledge or because they can't create their own mental structures (İskenderoğlu, 2010). Another difference between the Turkish and the Spanish sample concerns the fourth proof. A big amount of Spanish prospective teachers do not complete this proof, because they are not familiar with trigonometry.

\section{Final Reflections}

Comparative studies aim to identify how education systems differ among countries. The main differences among countries are teacher training programs, mathematics curriculum, courses, assessment, policy implications, country level variation, how much do the institutions vary (Mendaglio, 2015; Schmidt et all, 2008). Comparative studies of mathematics education aim to determine and explain differences of homologous phenomena in related contexts. Chang (1984) determined the differences in mathematics education between Taiwan, China and US. This study focuses on these countries' mathematics curriculum, teaching methods, and teacher training. According to the results of that study, the main differences among countries are curriculum, graduation requirements, instructional methods, classroom management, faculty evaluation, remediation, teacher training, in-service training, and the future of the teaching profession. It is known that proof education among countries differs. Ruan (1996) shows that there are significant differences in deductive proof education between US and China. The main differences between two countries' proof education are mathematics curriculum, instructions, examinations, supplementary materials, and how teachers and students perceive geometry. In our study we focused on the proof schemes of prospective mathematics teachers from Turkey and Spain. According to the results there are similarities and differences between proving of both countries. Further studies are needed to investigate the causes of the differences between proof schemes and proving of students among countries. Finding of such comparative studies will help educators and researchers classify students' proof schemes and proof writing. Thus it will be possible to evaluate holistically the results of these small scale qualitative studies and large scale studies like TIMMS.

\section{Acknowledgements}

The Spanish Government (EDU2016-81994-REDT), and the Research Centre COIDESO (University of Huelva, Spain) supported this research.

\section{References}

Almeida, D. (1996). Variation in proof standards: Implications for mathematics education. International Journal of Mathematical Education in Science and Technology, 27(5), 659-665. https://doi.org/10.1080/0020739960270504

Almeida, D. (2003). Engendering proof attitudes: can the genesis of mathematical knowledge teach us anything? International Journal of Mathematical Education in Science and Technology, 34(4), 479-488. https://doi.org/10.1080/0020739031000108574

Andrews, P. (2007). Negotiating meaning in cross-national studies of mathematics teaching: kissing frogs to find princes. Comparative Education, 43(4), 489-509. https://doi.org/10.1080/03050060701611888

Artigue, M., \& Winsløw, C. (2010). International comparative studies on mathematics education: A viewpoint from the anthropological theory of didactics. Recherches en didactiques des mathématiques, 30(1), 47-82.

Baker, J. D. (1996). Students' Difficulties with Proof by Mathematical Induction. Paper presented at the Annual Meeting of the American Educational Research Association, New York. 
Balacheff, N. (1988). Aspects of proof in pupils' practice of school mathematics. Mathematics, teachers and children, 216, 235.

Battista, M. T., \& Clements, D. H. (1995). Geometry and proof. Mathematics Teacher, 88(1), 48-54. Retrieved from https://www.nctm.org

CadwalladerOlsker, T. (2011). What do we mean by mathematical proof? Journal of Humanistic Mathematics, 1(1), 33-60. https://doi.org/10.5642/jhummath.201101.04

Chang, P. T. (1984). A comparative study of mathematics education between the province of Taiwan. Republic of China, and the United States. Republic of China: Pacific Cultural Foundation. (ERIC Document Reproduction Service No. ED 248 142)

Clarke, D. (2003). International comparative research in mathematics education. In A. J. Bishop, M.A. Clements, C. Keitel, J. Kilpatrick, \& F.K.S. Leung (Eds.), Second International Handbook of Mathematics Education, Part One (pp. 143-184). Dordrecht: Kluwer Academic Publishers.

Coe, R., \& Ruthven, K. (1994). Proof practices and constructs of advanced mathematics students. British Educational Research Journal, 20(1), 41-53. https://doi.org/10.1080/0141192940200105

Dreyfus, T. (1999). Why Johnny can't prove. Educational Studies in Mathematics, Vol. 38, No. 1/3, Forms of Mathematical Knowledge: Learning and Teaching with Understanding, 85-109. https://doi.org/10.1007/978-94-017-1584-3_5

Ernest, P. (1984). Mathematical induction: A pedagogical discussion. Educational Studies in Mathematics, 15(2), 173-189. https://doi.org/10.1007/BF00305895

Hanna, G. (2016) Reflections on proof as explanation. Paper presented in Topic Study Group 18, 13th International Congress on Mathematical Education, Hamburg, 24-31 July 2016.

Harel, G. (2008). DNR perspective on mathematics curriculum and instruction, Part I: focus on proving. ZDM, 40(3), 487-500. https://doi.org/10.1007/s11858-008-0104-1

Harel, G., \& Sowder, L. (1998). Students' proof schemes: results from exploratory studies. In A. H. Schoenfeld, J. Kaput, \& E. Dubinsky (Eds.), Research in collegiate mathematics III (pp.234-282). Providence, Rhode Island: American Mathematical Society. https://doi.org/10.1090/cbmath/007/07

Harel, G., \& Sowder, L. (2007). Toward comprehensive perspectives on the learning and teaching of proof. Second handbook of research on mathematics teaching and learning, 2, 805-842.

Hersh, R. (1993). Proving is convincing and explaining. Educational Studies in Mathematics, 24(4), 389-399. https://doi.org/10.1007/BF01273372

Hilbert, T. S., Renkl, A., Kessler, S., \& Reiss, K. (2008). Learning to prove in geometry: Learning from heuristic examples and how it can be supported. Learning and Instruction, 18(1), 54-65. https://doi.org/10.1016/j.learninstruc.2006.10.008

Housman, D., \& Porter, M. (2003). Proof schemes and learning strategies of above average mathematics students. Educational Studies in Mathematics, 53, 139-158. https://doi.org/10.1023/A:1025541416693

Hoyles, C. (1997). The curricular shaping of students' approaches to proof. For the Learning of Mathematics, 17(7), 7-16

Martin, W. G., Harel, G. (1989). Proof frames of pre-service elementary teachers. Journal for Research in Mathematics Education, 20(1), 41-51. https://doi.org/10.2307/749097

Mendaglio, A. (2015). A Comparative Review of Mathematics Educational Strategies in Ontario and Finland. Fields Mathematics Education Journal, 2(1).

Merriam, S. B. (2009). Qualitative research a guide to design and implementation. Jossey-Bass: San Fransisco

Moore, R. C. (1994). Making the transition to formal proof. Educational Studies in mathematics, 27(3), 249-266. https://doi.org/10.1007/BF01273731

Morali, S., Uğurel, I., Türnüklü, E., \& Yeşildere, S. (2006). Mathematics Student Teachers' Views on Proving. Kastamonu Eğitim Dergisi, 14(1), 147-160.

Oflaz, G., Bulut, N., \& Akcakin, V. (2016). Pre-Service Classroom Teachers' Proof Schemes in Geometry: A Case Study of Three Pre-Service Teachers. Eurasian Journal of Educational Research, 63, 133-152. https://doi.org/10.14689/ejer.2016.63.8 
Raman, M. (2003). Key ideas: What are they and how can they help us understand how people view proof? Educational studies in mathematics, 52(3), 319-325. https://doi.org/10.1023/A:1024360204239

Ruan, Z. (1996). A comparative study of deductive proofs in geometry education between the US and the People's Republic of China (Doctoral dissertation, Memorial University of Newfoundland).

Schmidt, W. H., Houang, R. T., Cogan, L., Blömeke, S., Tatto, M. T., Hsieh, F. J., \& Schwille, J. (2008). Opportunity to learn in the preparation of mathematics teachers: its structure and how it varies across six countries. ZDM, 4O(5), 735-747. https://doi.org/10.1007/s11858-008-0115-y

Schwarz, B., \& Kaiser, G. (2009). Professional competence of future mathematics teachers on argumentation and proof and how to evaluate it. Proof and Proving in Mathematics Education. ICMI Study, 19, 190-195.

Schwarz, B., Leung, I. K. C, Kaiser, G., Stillman, G., Brown, J., \& Vale, C. (2008). Future teachers' professional knowledge on argumentation and proof - Results from Australia, Germany, Hong Kong. ZDM: The International Journal on Mathematics Education, 40(5), 791-811. https://doi.org/10.1007/s11858-008-0150-8

Schwarz, B., Leung, I. K., Buchholtz, N., Kaiser, G., Stillman, G., Brown, J., \& Vale, C. (2008). Future teachers' professional knowledge on argumentation and proof: a case study from universities in three countries. ZDM, 40(5), 791-811. https://doi.org/10.1007/s11858-008-0150-8

Skemp, R.R. (1978). Relational understanding and instrumental understanding. Arithmetic Teacher, 26(3), 9-15.

Sowder, L., \& Harel, G. (2003). Case studies of mathematics majors' proof understanding, production, and appreciation. Canadian Journal of Math, Science \& Technology Education, 3(2), 251-267. https://doi.org/10.1080/14926150309556563

Van Dormolen, J. (1977). Learning to understand what giving a proof really means. Educational Studies in Mathematics, 8(1), 27-34. https://doi.org/10.1007/BF00302502

Van Hiele, P. M. (1986). Structure and insight. New York: Academic.

VanSpronsen, H. D. (2008). Proof processes of novice mathematics proof writers. University of Montana.

Weber, K., \& Alcock, L. (2004). Semantic and syntactic proof productions. Educational studies in mathematics, 56(2-3), 209-234. https://doi.org/10.1023/B:EDUC.0000040410.57253.a1

Xenofontos, C. (2010). International comparative research on mathematical problem solving: Suggestions for new research directions. CERME 6 (pp. 2523-2532).

\section{Copyrights}

Copyright for this article is retained by the author(s), with first publication rights granted to the journal.

This is an open-access article distributed under the terms and conditions of the Creative Commons Attribution license (http://creativecommons.org/licenses/by/4.0/). 